Article

\title{
Experimental and Modeling of Dicamba Adsorption in Aqueous Medium Using MIL-101(Cr) Metal-Organic Framework
}

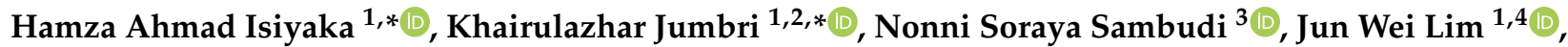 \\ Bahruddin Saad ${ }^{1}$, Anita Ramli ${ }^{1,4}\left[\right.$ and Zakariyya Uba Zango ${ }^{1}$
}

1 Department of Fundamental and Applied Sciences, Universiti Teknologi PETRONAS, Seri Iskandar 32610, Perak, Malaysia; junwei.lim@utp.edu.my (J.W.L.); bahruddin.saad@utp.edu.my (B.S.); anita_ramli@utp.edu.my (A.R.); zakariyya_17008416@utp.edu.my (Z.U.Z.)

2 Centre of Research in Ionic Liquids (CORIL), Institute of Contaminant Management, Universiti Teknologi PETRONAS, Seri Iskandar 32610, Perak, Malaysia

3 Department of Chemical Engineering, Universiti Teknologi PETRONAS, Seri Iskandar 32610, Perak, Malaysia; soraya.sambudi@utp.edu.my

4 HICoE-Centre for Biofuel and Biochemical Research, Institute of Self-Sustainable Building, Universiti Teknologi PETRONAS, Seri Iskandar 32610, Perak, Malaysia

* Correspondence: hamza_18001996@utp.edu.my (H.A.I.); khairulazhar.jumbri@utp.edu.my (K.J.)

check for updates

Citation: Isiyaka, H.A.; Jumbri, K.; Sambudi, N.S.; Lim, J.W.; Saad, B.;

Ramli, A.; Zango, Z.U. Experimental and Modeling of Dicamba

Adsorption in Aqueous Medium Using MIL-101(Cr) Metal-Organic Framework. Processes 2021, 9, 419. https://doi.org/10.3390/pr9030419

Academic Editor: María

V. López-Ramón

Received: 28 December 2020

Accepted: 18 January 2021

Published: 26 February 2021

Publisher's Note: MDPI stays neutral with regard to jurisdictional claims in published maps and institutional affiliations.

Copyright: (c) 2021 by the authors. Licensee MDPI, Basel, Switzerland. This article is an open access article distributed under the terms and conditions of the Creative Commons Attribution (CC BY) license (https:// creativecommons.org/licenses/by/ $4.0 /)$.

\begin{abstract}
Drift deposition of emerging and carcinogenic contaminant dicamba (3,6-dichloro-2methoxy benzoic acid) has become a major health and environmental concern. Effective removal of dicamba in aqueous medium becomes imperative. This study investigates the adsorption of a promising adsorbent, MIL-101(Cr) metal-organic framework (MOF), for the removal of dicamba in aqueous solution. The adsorbent was hydrothermally synthesized and characterized using $\mathrm{N}_{2}$ adsorptiondesorption isotherms, Brunauer, Emmett and Teller (BET), powdered X-ray diffraction (XRD), Fourier Transformed Infrared (FTIR) and field emission scanning electron microscopy (FESEM). Adsorption models such as kinetics, isotherms and thermodynamics were studied to understand details of the adsorption process. The significance and optimization of the data matrix, as well as the multivariate interaction of the adsorption parameters, were determined using response surface methodology (RSM). RSM and artificial neural network (ANN) were used to predict the adsorption capacity. In each of the experimental adsorption conditions used, the ANN gave a better prediction with minimal error than the RSM model. The MIL-101(Cr) adsorbent was recycled six times to determine the possibility of reuse. The results show that MIL-101(Cr) is a very promising adsorbent, in particular due to the high surface area $\left(1439 \mathrm{~m}^{2} \mathrm{~g}^{-1}\right)$, rapid equilibration ( $\left.25 \mathrm{~min}\right)$, high adsorption capacity $\left(237.384 \mathrm{mg} \mathrm{g}^{-1}\right)$ and high removal efficiency of $99.432 \%$.
\end{abstract}

Keywords: adsorption; dicamba; artificial neural network model; response surface methodology; metal-organic framework

\section{Introduction}

Anthropogenic activities such as crop cultivation, industrial processes and sewage discharge result in the contamination of surface and ground water resources [1]. Herbicides such as dicamba (3,6-dichloro-2-methoxy benzoic acid) are widely used to selectively kill broad leave weeds that affect crop areas, gardens and road sides [2]. When applied in excess, their residue remains in the environment and can be transported from point source to nonpoint sources through leaching, run-off, subsurface drainage and spray drift [3]. Drift deposition of dicamba to non-intended areas has become a major environmental concern, as it directly affects vulnerable crops even at low concentrations [4]. In the United States of America (USA), an estimate of 1.5 million hectares of non-target soybeans were destroyed by dicamba herbicides in 2017 due to uncontrolled drift and extend to 2018. The 
US Environmental Protection Agency (USEPA) implemented restrictio on the application of dicamba in 2018. In 2019 the USEPA canceled the registration of dicamba herbicide that restrict farmers to buy and use the products legally (USEPA, 2020).

The US and European Community Environmental Protection Agencies have listed dicamba as a priority pollutant with possible carcinogenic and mutagenic effects [5]. Dicamba is easily bioaccumulated and biomagnified in the tissues of plants and aquatic animals, which poses a serious health risk to humans and the environment at large [6]. Despite the environmental and health consequences of dicamba, many countries still adopt it as an alternative to pest control. Hence, the removal of this toxic contaminant from water becomes imperative.

Over the years, several physical and chemical treatment techniques such as advanced oxidation process, adsorption, bioremediation, membrane filtration have been applied for the removal of toxic contaminants in water [7]. One promising method that has been singled out and applied for the remediation of recalcitrant contaminants in water is adsorption, due to its low cost, simple operations, high selectivity, environmental benignity, convenient recycling and availability of alternative materials [8,9]. Adsorbents such as mesoporous silica [10], polymer [11] and clay material [12] have also been tested for the removal of dicamba in aqueous medium. Yet, the ideal adsorbent for real world application with high surface area, large pore volume, good water and thermal stability, fast equilibration time and easy regeneration remains elusive [13].

Recently, porous materials such as metal-organic frameworks (MOFs) have received considerable attention from researchers for application in water treatment, catalysis, gas sensing, biomedical imaging and drug delivery [14,15]. MOFs are a new class of advanced and porous materials that consist of a cluster of transition metal ion and organic linkers. The high surface area, porous nature, multifunctionality, tunable pore size make MOFs a unique material of interest in wastewater remediation $[16,17]$. Among the several MOFs reported, the MIL-101(Cr) is an exceptionally promising material that has been applied for the removal of contaminants such as pharmaceuticals, dyes and heavy metals in wastewaters [18]. The MIL-101(Cr) is formed from a combination of chromium (III) oxide octahedral trimers and dicarboxylate linker, resulting in a high class of hybrid supertetrahedron azeotypic mesoporous material [19].

The majority of adsorption studies only vary one parameter at a time; however, it has been recognized that several parameters often act simultaneously on the adsorption process. This conventional 'one-parameter-at-a-time' optimization approach is not only time consuming, costly for industrial applications, but the shared interactions and impacts of other parameters working together are not considered. In this study, we introduce a mathematical and intelligent algorithm that works like the structure of the human neurons using the central composite design response surface methodology and artificial intelligence. This is done to determine the effects and provide due consideration to the shared interactions of the adsorption process between dicamba and MIL-101(Cr) MOF. Additionally, the kinetics, isotherms and thermodynamic processes that affect the adsorption were also studied.

\section{Materials and Methods}

Chromium nitrate nonahydrate $\left(\mathrm{Cr}\left(\mathrm{NO}_{3}\right)_{3} \cdot 9 \mathrm{H}_{2} \mathrm{O}, 99 \%\right)$, 1,4-benzene dicarboxylic acid $\left(\mathrm{H}_{2} \mathrm{BDC}, 99 \%\right)$, hydrochloric acid $(\mathrm{HCl}), \mathrm{HF}(98 \%)$, acetone $(98 \%)$, $\mathrm{N}$-dimethyl formamide (DMF, 99\%), ethanol (99.9\%), methanol (99\%), and sodium hydroxide were purchased from Avantis Laboratory (Perak, Malaysia) and were used without further purification. Dicamba was sourced from Sigma-Aldrich (St. Louis, MO, USA).

\subsection{Synthesis of MIL-101(Cr) MOF}

The adsorbent was synthesized hydrothermally based on a previously reported process [20]. $\mathrm{Cr}\left(\mathrm{NO}_{3}\right)_{3} \cdot 9 \mathrm{H}_{2} \mathrm{O}(8 \mathrm{~g})$ and $\mathrm{H}_{2} \mathrm{BDC}(3.32 \mathrm{~g})$ were put in a $100 \mathrm{~mL}$ volumetric flask containing deionized water. The solution was stirred using a magnetic stirrer and sonicated for $30 \mathrm{~min}$, respectively, for it to be homogenized. HF $(10 \mathrm{mmol})$ was gradually added 
to the mixture and stirred for $15 \mathrm{~min}$. The solution was then placed in a stainless-steel Teflon-lined autoclave, sealed, and inserted into a preheated electric oven at $483 \mathrm{~K}$ for $8 \mathrm{~h}$. Next, the autoclave was allowed to cool to room temperature and the product was filtered and recovered. The as-synthesized product was further purified using deionized water, DMF and ethanol to remove possible impurities in the pores. The purified product was finally dried overnight, cooled to room temperature, and stored in a desiccator prior to use.

\subsection{Characterization of $M I L-101(\mathrm{Cr})$ Adsorbent}

The BET surface area and pore size of the MOF were analyzed by Micrometric ASAP 2020 using the $\mathrm{N}_{2}$ adsorption-desorption isotherm. The crystallinity and structural properties of the adsorbent were recorded on a Bruker D8 advanced X-ray diffraction (XRD). Perkin Elmer FTIR Spectrometer was used to ascertain the functional group of the material, which was scanned from 400 to $4000 \mathrm{~cm}^{-1}$. The morphology of the MOF was determined by field emission scanning electron microscopy (FESEM) using the Zeiss supra 55 VP instrument.

\subsection{Batch Adsorption Studies}

Adsorption studies were done by preparing a stock solution of dicamba $\left(1000 \mathrm{mg} \mathrm{L}^{-1}\right)$. A total of $100 \mathrm{mg}$ of the analyte was dissolved in a volumetric flask of $1000 \mathrm{~mL}$ and was stored at a temperature of $0{ }^{\circ} \mathrm{C}$ in a refrigerator before use. From the prepared stock, solutions containing different initial concentrations $\left(5-50 \mathrm{mg} \mathrm{L}^{-1}\right)$ were studied by dispersing $20 \mathrm{mg}$ of MIL-101(Cr) adsorbent in $100 \mathrm{~mL}$ conical flask. The total volume of $50 \mathrm{~mL}$ was maintained in the experiments. Next, the flask containing different concentrations were then inserted into a temperature regulated (incubator ES 20/60, Biosan, Riga, Latvia) and shaken at $150 \mathrm{rpm}$ for $1 \mathrm{~h}$. At an interval of $5 \mathrm{~min}$, the $2 \mathrm{~mL}$ sample solution was taken out and filtered using a $0.45 \mu \mathrm{m}$ nylon syringe membrane. The absorbance of the analyte solution was measured in a UV-vis spectrophotometer (Shimadzu Lamda 25, Waltham MA, USA). The $\mathrm{pH}$ in which the adsorption took palace was studied by varying the $\mathrm{pH}$ from 2 to 12, and the effect of temperature was studied from 25 to $50{ }^{\circ} \mathrm{C}$. The dosage was also studied by varying the quantity of adsorbent from 5 to $50 \mathrm{mg}$. All the adsorption data were recorded in triplicates from which the average values were calculated. The quantity of dicamba adsorbed at equilibrium $\left(\mathrm{q}_{\mathrm{e}}\right)$, percentage removal $(\% \mathrm{R})$ and quantity adsorbed at a time interval $\left(q_{t}\right)$ were calculated using the following equations:

$$
\begin{aligned}
\mathrm{q}_{\mathrm{e}} & =\frac{\left(\mathrm{C}_{\mathrm{o}}-\mathrm{C}_{\mathrm{e}}\right) \mathrm{V}}{\mathrm{w}} \\
\% \mathrm{R} & =\frac{\left(\mathrm{C}_{\mathrm{o}}-\mathrm{C}_{\mathrm{t}}\right)}{\mathrm{C}_{\mathrm{o}}} \times 100 \\
\mathrm{q}_{\mathrm{t}} & =\frac{\left(\mathrm{C}_{\mathrm{o}}-\mathrm{C}_{\mathrm{t}}\right) \mathrm{V}}{\mathrm{w}}
\end{aligned}
$$

where $C_{o}$ is the initial concentration, $C_{t}$ and $C_{e}$ are the time and equilibrium dicamba concentration $\left(\mathrm{mg} \mathrm{g}^{-1}\right), \mathrm{V}$ represents the solution volume $(\mathrm{L})$, and $\mathrm{w}$ is the adsorbent weight $(\mathrm{g})$.

\subsection{Adsorption Kinetics Studies}

Adsorption kinetics is an important model that describes the rate of adsorbate uptake, adsorption mechanism and the equilibrium time for the adsorption process. It is used to determine the effectiveness and efficiency of the adsorbent material as well as the mass transfer, which explains the rate-limiting steps in designing the adsorption system [21]. The kinetics results were fitted using the pseudo-first order, pseudo-second order and intraparticle diffusion model, as described in the equation below [21,22].

Pseudo-first-order model

$$
\mathrm{q}_{\mathrm{t}}=\mathrm{q}_{\mathrm{e}}\left(1-\mathrm{e}^{-\mathrm{k}_{1} \mathrm{t}}\right)
$$


Pseudo-second-order model

$$
\mathrm{q}_{\mathrm{t}}=\frac{\mathrm{K}_{2} \mathrm{q}_{\mathrm{e}}^{2} \mathrm{t}}{1+\mathrm{K}_{2} \mathrm{q}_{\mathrm{e}} \mathrm{t}}
$$

Intraparticle diffusion model

$$
\mathrm{q}_{\mathrm{t}}=\mathrm{K}_{\mathrm{P}} \mathrm{t}^{0.5}+\mathrm{C}
$$

where $q_{t}$ and $q_{e}$ are the amount of dicamba adsorbed at certain equilibrium and time, $\mathrm{t}\left(\mathrm{mg} \mathrm{g}^{-1}\right), \mathrm{K}_{1}\left(\mathrm{~min}^{-1}\right)$ is the pseudo-first-order rate constant, $\mathrm{K}_{2}\left(\mathrm{~g} \mathrm{mg}^{-1} \mathrm{~min}^{-1}\right)$ is the equilibrium rate constant of the pseudo-second-order and the intra-particle diffusion rate constant is represented as $\mathrm{K}_{\mathrm{p}}\left(\mathrm{mg} \mathrm{g}^{-1} \mathrm{~min}^{-1}\right)$.

\subsection{Adsorption Isotherm Studies}

The isotherm model is used to describe the interaction mechanism that exists between the adsorbate molecules with the adsorbent surface. Three isotherm models (Langmuir, Freundlich and Temkin isotherms) were used to evaluate the experimental data. The Langmuir isotherm depicts a monolayer adsorption interaction. The following equation was used to analyze the model [23].

$$
\begin{gathered}
\frac{\mathrm{C}_{\mathrm{e}}}{\mathrm{q}_{\mathrm{e}}}=\frac{1}{\mathrm{~K}_{\mathrm{L}} \mathrm{q}_{\mathrm{m}}}+\frac{\mathrm{C}_{\mathrm{e}}}{\mathrm{q}_{\mathrm{m}}} \\
\mathrm{R}_{\mathrm{L}}=\frac{1}{1+\mathrm{C}_{\mathrm{o}} \mathrm{K}_{\mathrm{L}}}
\end{gathered}
$$

where $\mathrm{C}_{\mathrm{e}}$ is the concentration at equilibrium $\left(\mathrm{mg} \mathrm{g}^{-1}\right)$, $\mathrm{q}_{\mathrm{e}}$ is the quantity of dicamba and dicamba adsorbed at equilibrium $\left(\mathrm{mg} \mathrm{g}^{-1}\right), \mathrm{q}_{\mathrm{m}}$ and $\mathrm{K}_{\mathrm{L}}$ are the constants representing adsorption capacity and adsorption energy, respectively. $\mathrm{R}_{\mathrm{L}}$ depicts the favorability of the adsorption process $\left(\mathrm{R}_{\mathrm{L}}>1\right.$, unfavorable; $0<\mathrm{R}_{\mathrm{L}}<1$, favorable; $\mathrm{R}_{\mathrm{L}}=1$, linear).

The Freundlich model describes a multilayer interaction on multiple adsorption sites.

$$
\log \left(\mathrm{q}_{\mathrm{e}}\right)=\log \mathrm{K}_{\mathrm{F}}+\frac{1}{\mathrm{n}} \log \mathrm{C}_{\mathrm{e}}
$$

where $\mathrm{K}_{\mathrm{F}}$ is the Freundlich constant of adsorption capacity, $\mathrm{n}$ is the adsorption intensity and $C_{e}$ is the equilibrium concentration of dicamba $\left(\mathrm{mg} \mathrm{g}^{-1}\right)$.

The Temkin model is represented by the following equation:

$$
\mathrm{q}_{\mathrm{e}}=\mathrm{B} \ln \mathrm{A}_{\mathrm{T}}+\mathrm{Bln}_{\mathrm{e}}
$$

where $B$ is the heat of adsorption (Jmol) and $A_{T}$ is the Temkin equilibrium binding constant corresponding with the maximum binding energy $\left(\mathrm{L} \mathrm{g}^{-1}\right)$.

\subsection{Thermodynamics Studies}

Thermodynamic parameters such as Gibbs free energy change $\left(\Delta \mathrm{G}^{\circ}\right)$, enthalpy change $\left(\Delta \mathrm{H}^{\circ}\right)$ and entropy change $\left(\Delta \mathrm{S}^{\circ}\right)$ were studied to assess the feasibility of the adsorption process based on temperature changes. This helps to determine whether the adsorption process is spontaneous, exothermic, or endothermic. The equations are given [24]:

$$
\begin{aligned}
\Delta \mathrm{G}^{\circ} & =-\mathrm{RT} \text { In } \mathrm{K}_{\mathrm{C}} \\
\Delta \mathrm{G}^{\circ} & =\Delta \mathrm{H}^{\circ}-\mathrm{T} \Delta \mathrm{S}^{\circ}
\end{aligned}
$$

where $\Delta \mathrm{G}^{\circ}$ is the free energy $\left(\mathrm{JK} \mathrm{mol}{ }^{-1}\right), \mathrm{T}(\mathrm{K})$ and $\mathrm{R}\left(\mathrm{JK} \mathrm{mol}^{-1}\right)$ are the temperature and universal gas constant for the adsorption, respectively, and $\mathrm{K}_{\mathrm{c}}$ is the equilibrium constant. 


\subsection{Optimization by Response Surface Methodology (RSM)}

The mathematical optimization of the shared interactions between the independent and dependent process parameters for the adsorption of dicamba onto MIL-101(Cr) was modeled using the central composite design (CCD) [25]. The data matrix design for the experimental and predicted values is expressed using a second-order polynomial equation, as described in Equation (13). The selected independent variables comprise of $\mathrm{pH}$, initial concentration, temperature, contact time and adsorbent dosage, while dicamba adsorption capacity was designed as the dependent variable. The accuracy and significance of the fitted model was ascertained by the analysis of variance (ANOVA) based on the probability value ( $p$-value) and the Fischer's test value ( $F$-value) at $95 \%$ confidence level. In addition, the coefficient of determination $\left(R^{2}\right), R^{2}$ adjusted $\left(R^{2}\right.$ adj) and predicted $R^{2}$ were used as diagnostic analyses to test the model performance [26].

$$
y=\beta_{0}+\sum_{i=1}^{k} \beta_{i} x_{i}+\sum_{i=1}^{k} \sum_{j \geq i}^{k} \beta_{i j} x_{i} x_{j}+\varepsilon
$$

where $\beta_{0}$ represents the constant term, $\beta_{i}$ and $\beta_{i j}$ describe the linear and interactive coefficient, respectively. $x_{i}, x_{j}$ define the independent variables, $k$ is the number of factors, $y$ is the predicted response and $\varepsilon$ is the noise or error detected in the reply.

\subsection{Artificial Neural Network (ANN) Model}

The ANN model for this study was designed using the multilayer-perceptron feedforward-artificial neural network (MLP-FF-ANN) with a back-propagation algorithm and activation function [27] to determine the dicamba adsorption capacity onto the MOF adsorbent material. The ANN model mimics the functionality of the biological system of the brain in disseminating information. The model can be subjected to learning process that can predict the pattern and correlate the experimental dataset during the training [28]. The method can be used to ascertain the effect of critical adsorption variables in the behavior of a given outcome. The designed model consists of multiple neurons that are structured in layers. The amount of selected hidden neurons were arrived at by trial through a process of weighted connections during the training process [29]. A total of $60 \%$ of the datasets were used to train the network, $20 \%$ for testing the model and $20 \%$ were used to validate the model. The training datasets were used to train the model by modifying the weight of the network through learning, the testing subset was applied to estimate the generalization ability of the network, and the network efficiency was determined using the validation dataset. Using this model, the diagnostic criteria including the root mean square error (RMSE) and Akaike information criteria (AIC), standard square error (SSE) were considered as the best fit to judge the performance of the adsorption process by regression analysis. The following equations were used:

$$
\begin{gathered}
\mathrm{R}^{2}=1-\frac{\sum\left(\mathrm{x}_{\mathrm{i}}-\mathrm{y}_{\mathrm{i}}\right)^{2}}{\sum \mathrm{y}_{\mathrm{i}}^{2}-\frac{\sum \mathrm{y}_{\mathrm{i}}^{2}}{\mathrm{n}}} \\
\mathrm{R}^{2} \mathrm{adj}=1-\left(1-\mathrm{R}^{2}\right)\left(\frac{\mathrm{n}-1}{\mathrm{n}-\mathrm{p}}\right) \\
\mathrm{RMSE}=\sqrt{\frac{1}{\mathrm{n}} \sum \frac{\mathrm{n}}{\mathrm{i}=1}\left(\mathrm{x}_{\mathrm{i}}-\mathrm{y}_{\mathrm{i}}\right)^{2}} \\
\mathrm{AIC}=\operatorname{nln}\left(\frac{\mathrm{SSE}}{\mathrm{n}}\right)+2 \mathrm{n}_{\mathrm{p}}+\frac{2 \mathrm{n}_{\mathrm{p}}\left(\mathrm{n}_{\mathrm{p}}+1\right)}{\mathrm{n}\left(\mathrm{n}_{\mathrm{p}}+1\right)}
\end{gathered}
$$

where $x_{i}$ is the data observation that was expressed experimentally, $y_{i}$ represents the data predicted, $\mathrm{n}$ and $\mathrm{p}$ are the number of observations and parameters. 


\subsection{Regeneration and Reuse of the Adsorbent}

The potential of recycling the MOF material after use is an important index to determine the quality of the adsorbent. After the adsorption experiments, the adsorbent was decanted, washed and filtered with water and acetone severally. The material was then dried in a vacuum at $80^{\circ} \mathrm{C}$ for $4 \mathrm{~h}$ and reused as adsorbent for the removal of dicamba in water. This was repeated for six cycles.

\section{Results}

\subsection{Characterization of the MOF}

The BET surface area of the MOF is $1439 \mathrm{~m}^{2} \mathrm{~g}^{-1}$, as highlighted in Table 1 and Figure 1a, which is typical of highly porous materials. The diffraction pattern of the MIL$101(\mathrm{Cr})$ (Figure 1b) adsorbent indicates peaks that are in agreement with those reported in previous studies $[30,31]$, confirming a well-formed crystallite structure of the MOF. The functional groups of the MOF are presented in the FTIR spectra in Figure 1c. The band at $567 \mathrm{~cm}^{-1}$ can be ascribed to the $\mathrm{Cr}-\mathrm{O}$ bond that represents the formation of a wellstructured material, and the peaks of 746 and $1287 \mathrm{~cm}^{-1}$ were attributed to the stretching of $\mathrm{C}-\mathrm{H}$ [32]. The sharp peak of $1384 \mathrm{~cm}^{-1}$ denotes a symmetric vibration that shows the presence of the dicarboxylate group in the MOF [33]. The peak at $1581 \mathrm{~cm}^{-1}$ is attributed to $C=C$ stretching vibration [34] and the strong-broad band around $3433 \mathrm{~cm}^{-1}$ shows the presence of the O-H group in the material [35]. The FESEM image of the MIL-101(Cr) (Figure 1d) is similar to that of a previous study [32].

Table 1. Surface properties of MIL-101(Cr) metal-organic framework (MOF).

\begin{tabular}{cc}
\hline Properties & MIL-101(Cr) \\
\hline BET surface area $\left(\mathrm{m}^{2} \mathrm{~g}^{-1}\right)$ & 1439 \\
Langmuir surface area $\left(\mathrm{m}^{2} \mathrm{~g}^{-1}\right)$ & 2124 \\
Micropore surface area $\left(\mathrm{m}^{2} \mathrm{~g}^{-1}\right)$ & 182 \\
Pore size $(\mathrm{nm})$ & 0.773 \\
\hline
\end{tabular}



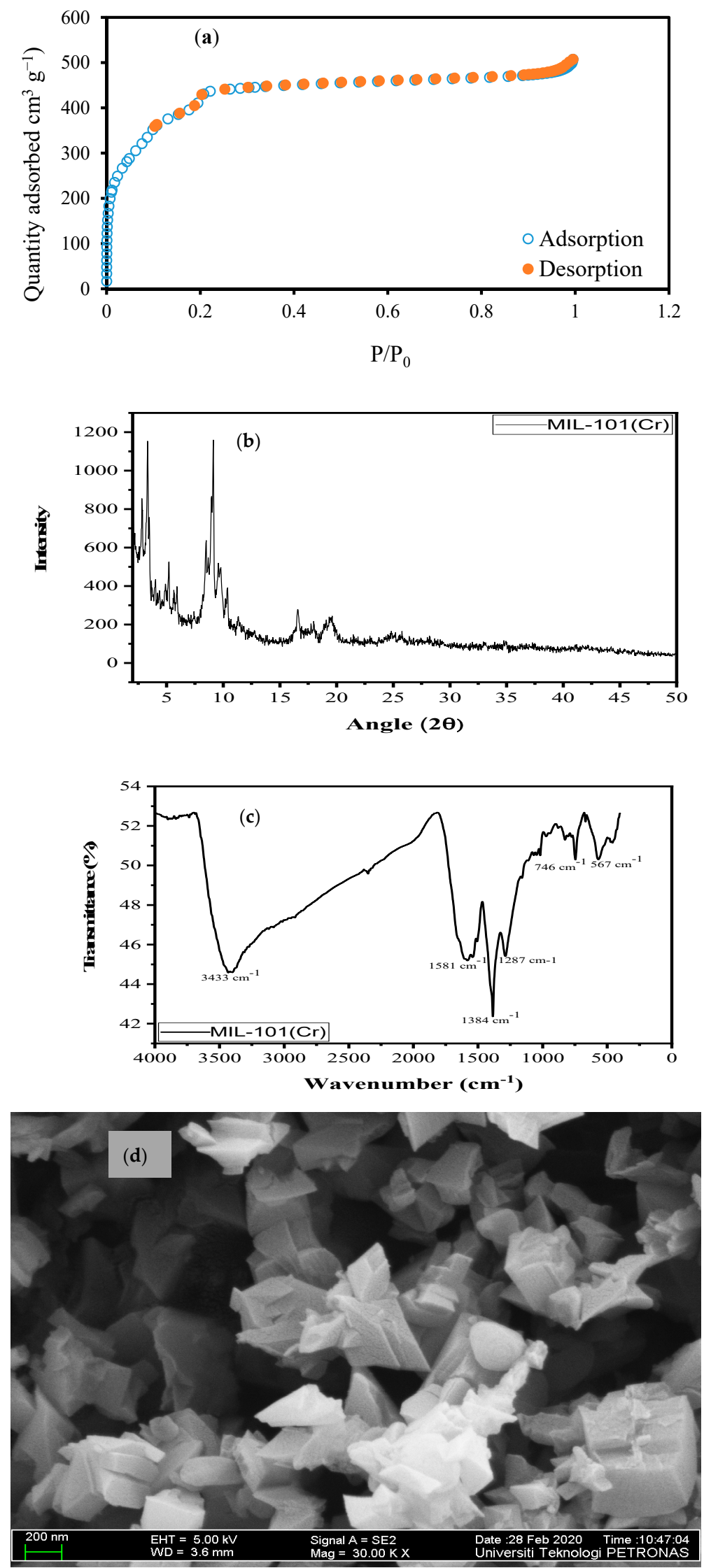

Figure 1. Characterization of the MOF (a) $\mathrm{N}_{2}$ adsorption-desorption isotherm, (b) XRD pattern, and (c) FTIR spectrum (d) FESEM spectrum of MIL-101(Cr). 


\subsection{Adsorption Kinetics Models}

The rate of adsorption uptake and equilibration time were used to determine the adsorption kinetics. Hence, the efficiency of the dicamba removal was ascertained at different initial concentrations ( 5 to $50 \mathrm{mg} \mathrm{L}^{-1}$ ), varied time from 5 to $60 \mathrm{~min}$, optimum $\mathrm{pH}$ condition $(\mathrm{pH} 4)$, dosage $(20 \mathrm{mg})$ and temperature $\left(40{ }^{\circ} \mathrm{C}\right)$. The result is shown in Figure 2. Rapid removal efficiency was recorded within the first 5 to $10 \mathrm{~min}$ of contact time, and the adsorption reached equilibrium in $\sim 25 \mathrm{~min}$ with high adsorption capacity of $237.384 \mathrm{mg} \mathrm{g}^{-1}$ due to favorable interaction, large pores, as well as active and vacant adsorption sites of MIL-101 (Cr). This coincides with the high surface area of the MOF $\left(1439 \mathrm{~m}^{2} \mathrm{~g}^{-1}\right)$. The contact time was extended until $60 \mathrm{~min}$ to ensure the maximum interaction of the molecule with the MOF after equilibrium was attained. The optimum condition of the kinetics studies with the highest adsorption capacity was attained with concentration of $50 \mathrm{mg} \mathrm{L}^{-1}, \mathrm{pH} 4$, dosage $20 \mathrm{mg}$, contact time $\sim 25 \mathrm{~min}$ and temperature $40^{\circ} \mathrm{C}$.

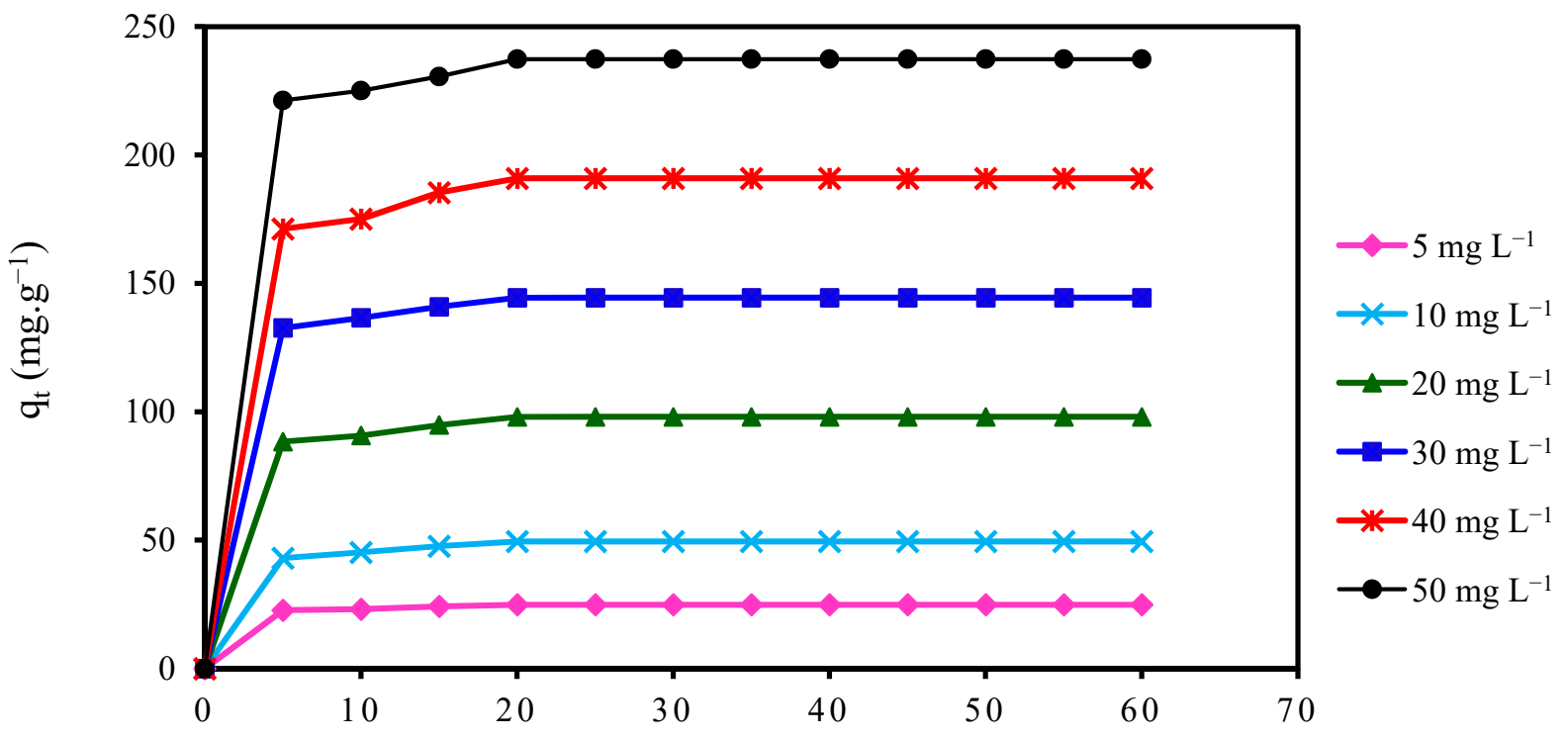

Time (min)

Figure 2. Effect of contact time on dicamba adsorption. Dosage: $20 \mathrm{mg}$; concentration, $5-50 \mathrm{mg} \mathrm{L}-1$; temp, $40{ }^{\circ} \mathrm{C}$; equilibrium time, $25 \mathrm{~min}$ and $150 \mathrm{rpm}$.

The values obtained for the different kinetic models are displayed in Table 2. The results show that the Pseudo-second order kinetics model best fit the experimental data with the highest coefficient of determination $\left(R^{2}=0.999\right), R^{2}$ adj $=0.997$, lowest $R M S E=0.003$ and the least AIC value of -133.8 . The $\mathrm{q}_{\mathrm{e}}$ values calculated for the pseudo-second order is in good agreement with the experimental findings. Hence, the Pseudo-second order model is represented in Figure S1a. The intraparticle diffusion mechanism was also used to describe the kinetics behaviors of the adsorption process based on the interaction and movement of the molecules inside the particles of the MOF adsorbent. The model describes a multiple linear relationship that follows a multistep mechanism. The multistage process is described in Figure S1b that represents an external diffusion of herbicides to the surface of the adsorbent from the bulk phase, and the transport of the molecules from the surface inside the pore of the MOF. 
Table 2. Adsorption kinetics parameters for the removal of dicamba.

\begin{tabular}{|c|c|c|c|c|c|c|c|c|}
\hline Pseudo-First Order & $\left(\mathrm{mg} \mathrm{L}^{-1}\right)$ & $\mathrm{q}_{\mathrm{e}, \exp }\left(\mathrm{mg} \mathrm{g}^{-1}\right)$ & $\mathrm{q}_{\mathrm{e}, \mathrm{cal}}\left(\mathrm{mg} \mathrm{g}^{-1}\right)$ & $K_{1}(\min )^{-1}$ & $\mathbf{R}^{2}$ & $R^{2}$ adj & RMSE & AIC \\
\hline & 5 & 24.860 & 10.432 & 0.152 & 0.08 & 0.744 & 0.753 & -1.393 \\
\hline & 10 & 49.504 & 29.224 & 0.181 & 0.945 & 0.927 & 0.717 & -1.395 \\
\hline & 20 & 98.011 & 57.512 & 0.205 & 0.803 & 0.737 & 0.723 & -1.769 \\
\hline & 30 & 144.423 & 79.885 & 0.223 & 0.797 & 0.729 & 0.795 & -0.853 \\
\hline & 40 & 190.903 & 133.499 & 0.235 & 0.832 & 0.776 & 0.686 & -2.321 \\
\hline & 50 & 237.384 & 133.686 & 0.236 & 0.729 & 0.639 & 0.886 & 0.232 \\
\hline \multirow[t]{7}{*}{ Pseudo-second order } & $\left(\mathrm{mg} \mathrm{L}^{-1}\right)$ & $\mathrm{q}_{\mathrm{e}, \exp }\left(\mathrm{mg} \mathrm{g}^{-1}\right)$ & $\mathrm{q}_{\mathrm{e}, \mathrm{cal}}\left(\mathrm{g} \mathrm{mg}^{-1}\right)$ & $K_{2}\left(\mathrm{~g} \mathrm{mg}^{-1} \min ^{-1}\right)$ & $\mathbf{R}^{2}$ & $R^{2}$ adj & RMSE & AIC \\
\hline & 5 & 24.860 & 24.875 & 0.117 & 0.997 & 0.995 & 0.052 & -74.97 \\
\hline & 10 & 49.504 & 49.751 & 0.041 & 0.998 & 0.995 & 0.027 & -92.23 \\
\hline & 20 & 98.011 & 98.039 & 0.027 & 0.999 & 0.997 & 0.003 & -110.5 \\
\hline & 30 & 144.423 & 144.927 & 0.023 & 0.996 & 0.995 & 0.009 & -120.6 \\
\hline & 40 & 190.903 & 192.307 & 0.012 & 0.995 & 0.994 & 0.007 & -127.8 \\
\hline & 50 & 237.384 & 238.095 & 0.016 & 0.995 & 0.994 & 0.005 & -133.8 \\
\hline \multirow[t]{7}{*}{ Intraparticle diffusion } & $\left(\mathrm{mg} \mathrm{L}^{-1}\right)$ & & \multicolumn{2}{|c|}{$\mathrm{Kp}\left(\mathrm{mg}^{-1} \mathrm{~g}^{-1} \mathrm{~min}^{1 / 2}\right) \mathrm{C}$} & $\mathbf{R}^{2}$ & $R^{2}$ adj & RMSE & AIC \\
\hline & 5 & & 2.048 & 8.736 & 0.579 & 0.438 & 5.232 & 1.211 \\
\hline & 10 & & 4.147 & 16.375 & 0.616 & 0.488 & 7.977 & 3.211 \\
\hline & 20 & & 8.099 & 33.913 & 0.588 & 0.45 & 9.949 & 4.493 \\
\hline & 30 & & 11.883 & 51.503 & 0.571 & 0.428 & 11.961 & 5.773 \\
\hline & 40 & & 15.837 & 65.345 & 0.59 & 0.453 & 14.848 & 9.951 \\
\hline & 50 & & 19.363 & 86.049 & 0.57 & 0.458 & 15.016 & 11.122 \\
\hline
\end{tabular}

\subsection{Dicamba Adsorption Isotherms}

The equilibrium data of the adsorption process was validated by the Langmuir, Freundlich and Temkin isotherm models to study the surface properties and interaction mechanism between the MOF and the adsorbate molecule. From the calculated results in Table S1 and Figure 3, the Freundlich isotherm model best fits the adsorption process based on the regression analysis with the highest $R^{2}=0.998, R^{2}$ adj (0.997); lowest RMSE (0.023) and the least AIC (-43.773) values. The Freundlich model shows a more linear curve that implies an adsorption process with multilayer interaction on heterogeneous surfaces with binding sites that are not equivalent [36].

(a) langmuir

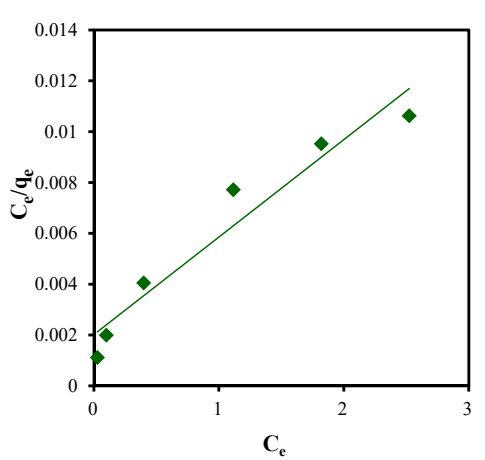

(b)Freudlinch

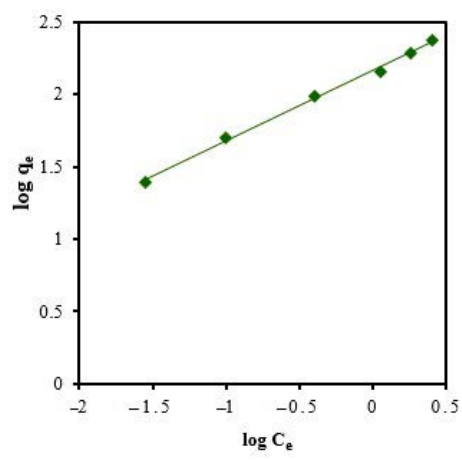

Temkin

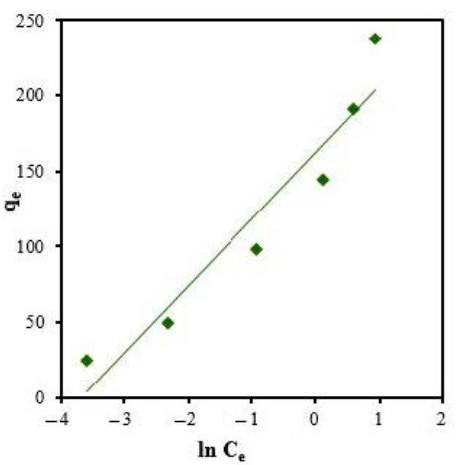

Figure 3. Isotherm adsorption models of dicamba. (a) Langmuir, (b) Freundlich, and (c) Temkin. Dosage: 20 mg; concentration of dicamba, $20 \mathrm{mg} \mathrm{L}^{-1}$; temperature, $40^{\circ} \mathrm{C}$; equilibration time, $25 \mathrm{~min}$ and $\mathrm{rpm}, 150$. 


\subsection{Effect of Temperature and Thermodynamic Studies}

The thermodynamic studies were conducted by varying the temperature from 25 to $50{ }^{\circ} \mathrm{C}$ to understand the spontaneity of the adsorption process (Figure 4). An increase in temperature leads to an increase in the adsorption of dicamba. As temperature rises, the viscosity of the solution decreases, which accelerates the mobility of the adsorbate molecules that facilitate the adsorption process [36]. The thermodynamic parameters are described in Table 3. The continuous decrease in the values of the Gibbs free energy $\left(\Delta \mathrm{G}^{\circ}\right)$ due to an increase in temperature indicates a spontaneous process in the adsorption of dicamba. The positive enthalpy change $\left(\Delta \mathrm{H}^{\circ}=27.920 \mathrm{~kJ} \mathrm{~mol}^{-1}\right)$ shows that the adsorption of dicamba unto MIL-101(Cr) is endothermic. Also, the positive values of the standard entropy change denotes the affinity and increased randomness at the liquid-solid interface between the MOF and dicamba during the adsorption process [31].

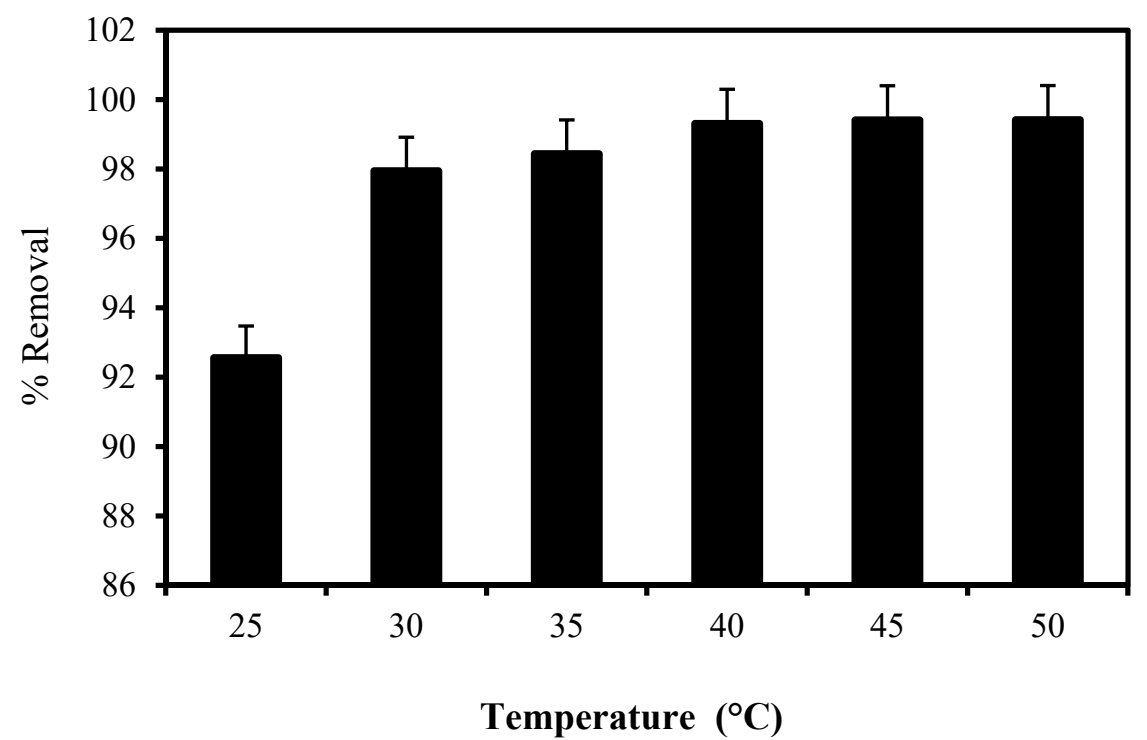

Figure 4. Effect of temperature on the dicamba adsorption (concentration of dicamba, $20 \mathrm{mg} \mathrm{L}^{-1}$; equilibration time, $25 \mathrm{~min}$; rpm, 150).

Table 3. Thermodynamic parameters for the adsorption of dicamba onto MIL-101(Cr).

\begin{tabular}{|c|c|c|c|}
\hline Temp $\left({ }^{\circ} \mathrm{C}\right)$ & $\Delta \mathrm{G}^{\circ}(\mathrm{kJ} \mathrm{mol}-1)$ & $\Delta \mathrm{H}^{\circ}(\mathrm{kJ} \mathrm{mol}-1)$ & $\Delta \mathrm{S}^{\circ}\left(\mathrm{kJ} \mathrm{mol}^{-1} \mathrm{~K}^{-1}\right)$ \\
\hline 25 & -155.781 & 27.920 & 522.850 \\
\hline 30 & -158.395 & & \\
\hline 35 & -161.009 & & \\
\hline 40 & -163.624 & & \\
\hline 45 & -166.238 & & \\
\hline 50 & -168.852 & & \\
\hline
\end{tabular}

\subsection{Optimization of Process Parameters by Response Surface Methodology (RSM)}

To study the interaction effect of the independent variables on the dicamba adsorption capacity $\left(\mathrm{q}_{\mathrm{e}} \mathrm{mg} \mathrm{g}^{-1}\right)$, the central composite design (CCD) was selected for the experimental design data matrix for the statistical analysis. Thus, the significance of the data was ascertained by the analysis of variance (ANOVA) in Table 4 , containing the Model $F$-value of 103.03 and $p$-values less than 0.05 . The model signifies a minimum chance of $0.01 \%$ that an $F$-value of this magnitude could exist by noise. The less $p$-values represent a statistically significant model that can be used to predict the dicamba adsorption capacity. The second order polynomial equation was developed using the data based on the coded factors as shown in Equation (18). The coded levels and experimental input design are shown in Table S2. The result obtained from the CCD-RSM multiple regression analysis gave a 
significant prediction with an $R^{2}=0.990, R^{2}$ adj $=0.979$ and $R^{2}$ predicted $=0.955$, which indicate a positive relationship between the experimental and predicted response values. Also, an adequate precision (AP) value of 37.738 that represents the ratio of response to noise, further describes the significance of the model used. Using the RSM model, the equation is represented as contact time (A), initial concentration (B), adsorbent dosage (C), $\mathrm{pH}(\mathrm{D})$, and temperature (E).

Adsorption capacity of Dicamba $\left(\mathrm{mg} \mathrm{g}^{-1}\right)=9.59+0.2910 \mathrm{~A}+2.58 \mathrm{~B}+0.0005 \mathrm{C}-0.0093 \mathrm{D}+0.0144 \mathrm{E}-$ $0.0135 \mathrm{AB}+0.0991 \mathrm{AC}+0.0984 \mathrm{AD}-0.0576 \mathrm{AE}+0.0689 \mathrm{BC}+0.0951 \mathrm{BD}-0.1031 \mathrm{BE}-0.0288 \mathrm{CD}+0.0201 \mathrm{CE}+$ $0.0372 \mathrm{DE}-0.0713 \mathrm{~A}^{2}-0.2494 \mathrm{~B}^{2}+0.0178 \mathrm{C}^{2}+0.0061 \mathrm{D}^{2}+0.0233 \mathrm{E}^{2}$

Table 4. Analysis of variance (ANOVA) for dicamba removal.

\begin{tabular}{|c|c|c|c|c|c|}
\hline Source & Sum of Square & df & Mean Square & $F$-Value & $p$-Value \\
\hline Model & 271.165 & 20 & 13.558 & 103.031 & $<0.0001$ \\
\hline A-Contact time & 2.800 & 1 & 2.800 & 21.279 & $<0.0001$ \\
\hline B-Initial concentration & 220.691 & 1 & 220.691 & 1677.078 & $<0.0001$ \\
\hline C-Adsorbent dosage & 9.130 & 1 & 9.126 & 6.940 & 0.993 \\
\hline D-pH & 0.002 & 1 & 0.00284 & 0.021 & 0.0431 \\
\hline E-Temperature & 0.006 & 1 & 0.006 & 0.052 & 0.0235 \\
\hline AB & 0.005 & 1 & 0.005 & 0.044 & $<0.0001$ \\
\hline $\mathrm{AC}$ & 0.298 & 1 & 0.298 & 2.271 & 0.0354 \\
\hline $\mathrm{AD}$ & 0.294 & 1 & 0.294 & 2.238 & $<0.0001$ \\
\hline $\mathrm{AE}$ & 0.111 & 1 & 0.111 & 0.849 & 0.3661 \\
\hline $\mathrm{BC}$ & 0.151 & 1 & 0.151 & 1.148 & 0.2949 \\
\hline $\mathrm{BD}$ & 0.287 & 1 & 0.287 & 2.188 & 0.1526 \\
\hline $\mathrm{BE}$ & 0.338 & 1 & 0.338 & 2.569 & 0.1225 \\
\hline CD & 0.026 & 1 & 0.026 & 0.200 & 0.6585 \\
\hline CE & 0.012 & 1 & 0.012 & 0.097 & 0.7576 \\
\hline $\mathrm{DE}$ & 0.044 & 1 & 0.044 & 0.335 & 0.5683 \\
\hline $\mathrm{A}^{2}{ }^{2}$ & 0.257 & 1 & 0.257 & 1.957 & 0.1750 \\
\hline $\mathrm{BA} \hat{A}^{2}$ & 2.744 & 1 & 2.744 & 20.858 & 0.0001 \\
\hline$C \hat{A}^{2}$ & 0.015 & 1 & 0.015 & 0.121 & 0.7310 \\
\hline $\mathrm{DA} \hat{A}^{2}$ & 0.001 & 1 & 0.001 & 0.014 & 0.9058 \\
\hline $\mathrm{EA}^{2}$ & 0.027 & 1 & 0.027 & 0.209 & 0.6516 \\
\hline Residual & 3.026 & 23 & 0.131 & & \\
\hline Lack of Fit & 3.026 & 22 & 0.137 & & \\
\hline Pure Error & 6.121 & 1 & 6.124 & & \\
\hline Cor Total & 274.192 & 43 & & & \\
\hline $\mathrm{R}^{2}$ & 0.990 & & & & \\
\hline $\mathrm{R}^{2} \mathrm{adj}$ & 0.979 & & & & \\
\hline $\mathrm{R}^{2}$ pred & 0.955 & & & & \\
\hline
\end{tabular}

The multivariate interaction between the independent variables that determine the dicamba adsorption capacity onto MIL-101(Cr) is depicted by the contour and 3D graph of the RSM plots in Figure 5. The optimum adsorption condition is given as contact time is $25 \mathrm{~min}$, initial concentration $50 \mathrm{mg} \mathrm{L}^{-1}$, adsorbent dosage $20 \mathrm{mg}$, $\mathrm{pH} 4$ and temperature $40{ }^{\circ} \mathrm{C}$. Hence, Figure 5 a describes the shared interaction between initial concentration (5-50 $\mathrm{mg} \mathrm{L}^{-1}$ ) and contact time (5 to $60 \mathrm{~min}$ ) with other parameters held at optimum conditions. It can be seen that the adsorption capacity increases with increase in the concentration of dicamba within a short time. The equilibration time of the adsorption is reached in $\sim 25 \mathrm{~min}$ and remain static with no further changes as the time extends to $1 \mathrm{~h}$. As the concentration increases, the force on the active and vacant pores of the adsorbent will be intensified. These values are closely correlated with the experimental ( $\left.\mathrm{q}_{\mathrm{e}}\right)$ values and calculated $\left(\mathrm{q}_{\mathrm{e}}\right)$ values of the kinetics model. The interaction between $\mathrm{pH}$ and time was also studied by varying the $\mathrm{pH}$ from 2 to 12, as shown in Figure 5b. Hence, when the $\mathrm{pH}$ is low (2 to 6), the solution of the herbicide will move to the anionic form, causing it to be negatively charged due to deprotonation, resulting to a positively charged MIL101(Cr) surface [30]. This causes an electrostatic interaction to take place, resulting in a high removal capacity due to the attraction of the negatively charged molecule with a positive surface of the adsorbent. An increase in the solution $\mathrm{pH}$ value by varying the range from 7 to 12 results in a negative charge surface of the MIL-101(Cr) thus, hindering the electrostatic interactions to take place that lead to reduction in the adsorption capacity. 
This can be caused by the strong competition for active vacant sites between the -OH and the herbicide molecules [37]. Also, when the $\mathrm{pH}$ of the solution is higher, some functional groups comprising of carbonyl and hydroxyl will be in their protonated cationic form, which retard efficient adoption. The influence of adsorbent dose and contact time on adsorption capacity is described in Figure $5 \mathrm{c}$. The adsorption increases as the adsorbent dose increase from 5 to $20 \mathrm{mg}$. Further increase in the dosage above $20 \mathrm{mg}$ did not result in a significant change in the adsorption capacity. As such, $20 \mathrm{mg}$ is selected as the optimum dose for the effective removal of dicamba.

(a) Dicamba adsorption capacity $\left(\mathrm{mg} \mathrm{g}^{-1}\right)$

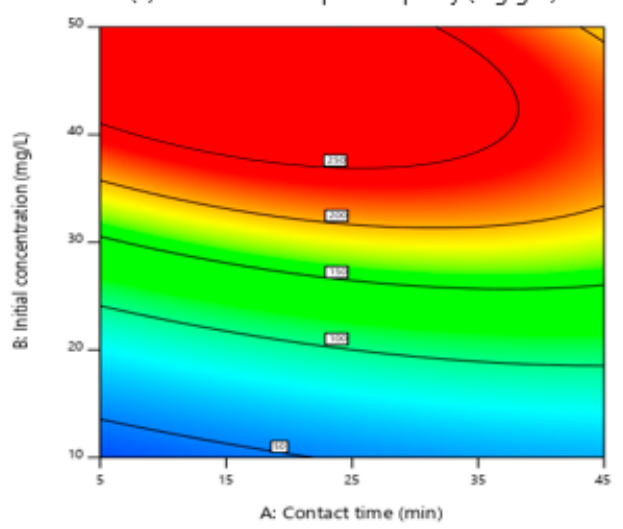

(b) Dicamba adsorption capacity ( $\mathrm{mg} \mathrm{g}^{-1}$ )

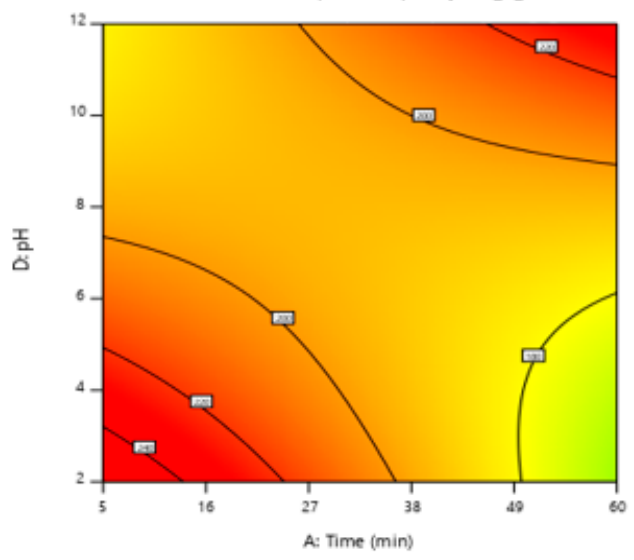

(c) Dicamba adsorption capacity ( $\mathrm{mg} \mathrm{g}^{-1}$ )

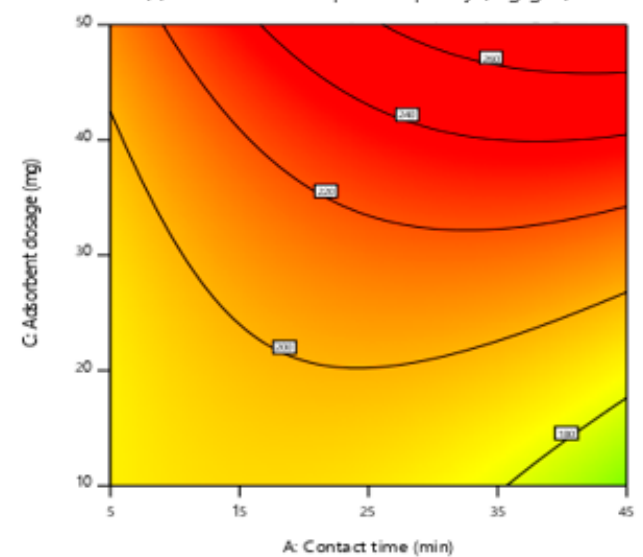

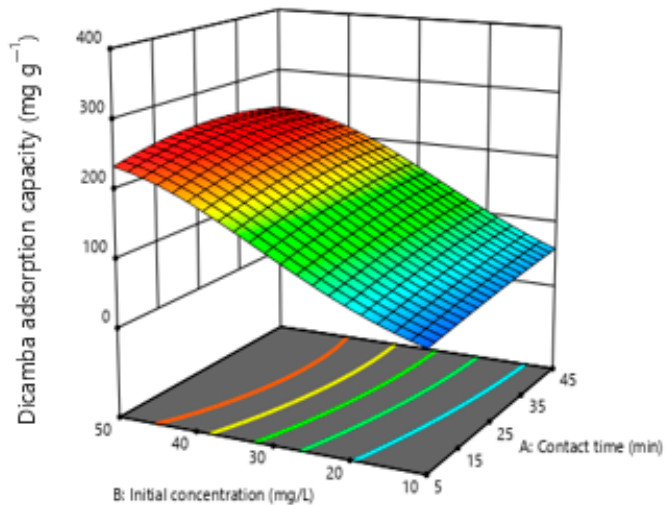
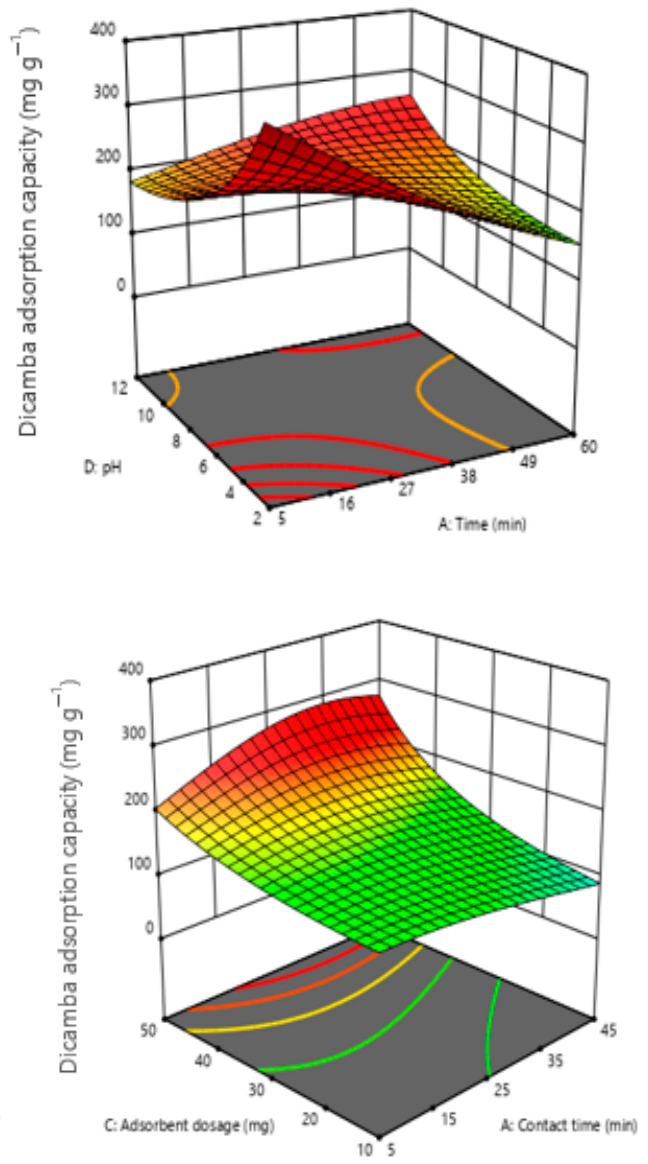

Figure 5. Multivariate interaction for adsorption capacity of dicamba $\left(\mathrm{mg} \mathrm{g}^{-1}\right)$, (a) initial dicamba concentration and contact time, (b) solution $\mathrm{pH}$ and contact time (c) adsorbent dosage and contact time. 


\subsection{Prediction Modeling by ANN}

The ANN architecture for this study consists of five predictor variables (contact time, initial concentration, adsorbent dosage, $\mathrm{pH}$, and temperature), eight hidden neurons and one output (dicamba adsorption capacity, $\mathrm{q}_{\mathrm{e}}\left(\mathrm{mg} \mathrm{g}^{-1}\right)$ ). Several topologies were trained, tested, and validated based on the trial and error approach to learn the pattern of the data for accurate prediction. The 5-8-1 topology developed after series of trial (Figure 6) gave the best prediction with good correlation with the experimental values, and $\mathrm{R}^{2}=0.999$, $\mathrm{R}^{2}$ adj $=0.992$ and $\mathrm{RMSE}=0.053$ as described in Table 5 .

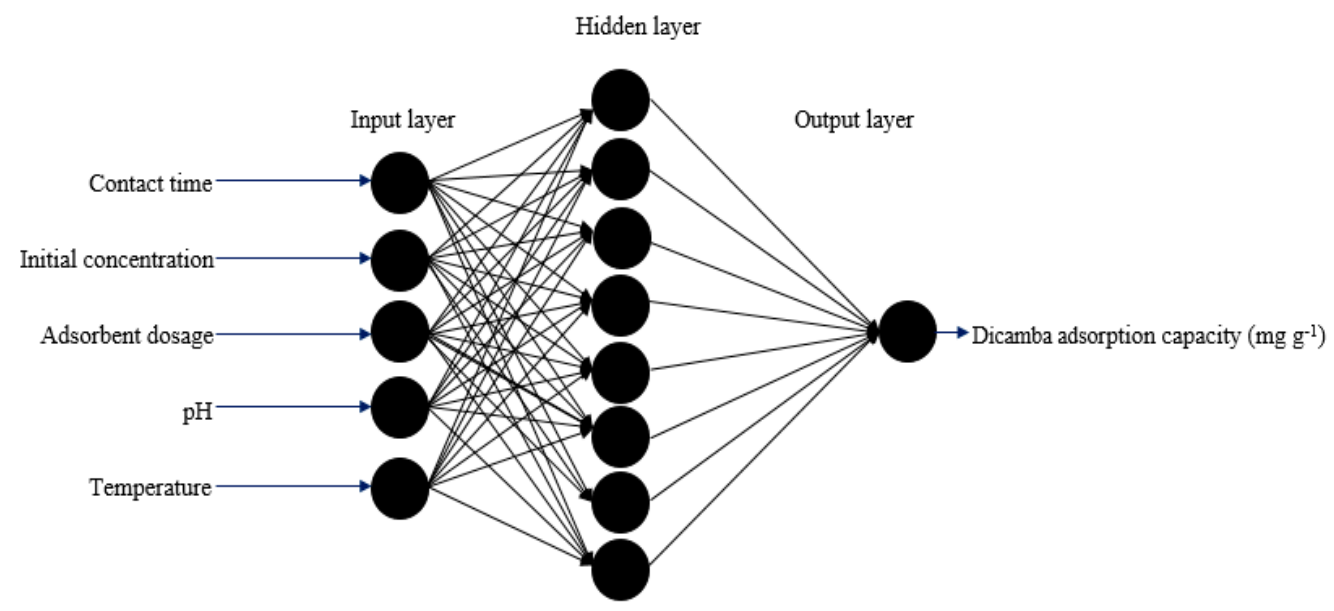

Figure 6. Artificial neural network architecture.

Table 5. Optimum conditions for designing the ANN prediction architecture.

\begin{tabular}{ccccccccccc}
\hline & & \multicolumn{3}{c}{ Training } & \multicolumn{3}{c}{ Testing } & \multicolumn{3}{c}{ Validation } \\
\cline { 3 - 10 } Numbers & Neurons & $\mathbf{R}^{\mathbf{2}}$ & $\mathbf{R}^{\mathbf{2}}$ adj & RMSE & $\mathbf{R}^{\mathbf{2}}$ & $\mathbf{R}^{\mathbf{2}}$ adj & $\mathbf{R M S E}$ & $\mathbf{R}^{\mathbf{2}}$ & $\mathbf{R}^{\mathbf{2}}$ adj & $\mathbf{R M S E}$ \\
\hline 1 & {$[3]$} & 0.992 & 0.988 & 4.774 & 0.966 & 0.951 & 3.012 & 0.988 & 0.901 & 2.930 \\
2 & {$[4]$} & 0.994 & 0.991 & 1.512 & 0.984 & 0.975 & 0.431 & 0.984 & 0.954 & 2.270 \\
3 & {$[5]$} & 0.987 & 0.975 & 0.958 & 0.990 & 0.983 & 1.011 & 0.991 & 0.986 & 0.824 \\
4 & {$[6]$} & 0.991 & 0.977 & 0.973 & 0.987 & 0.981 & 0.621 & 0.986 & 0.911 & 0.716 \\
5 & {$[7]$} & 0.993 & 0.991 & 0.403 & 0.991 & 0.980 & 1.006 & 0.984 & 0.972 & 0.531 \\
6 & {$[8]$} & 0.999 & 0.992 & 0.053 & 0.998 & 0.996 & 0.033 & 0.994 & 0.988 & 0.043 \\
7 & {$[9]$} & 0.995 & 0.991 & 0.061 & 0.993 & 0.988 & 1.210 & 0.996 & 0.941 & 0.094 \\
8 & {$[10]$} & 0.998 & 0.981 & 0.166 & 0.995 & 0.992 & 0.922 & 0.992 & 0.987 & 0.428 \\
9 & {$[55]$} & 0.988 & 0.985 & 0.975 & 0.977 & 0.969 & 0.221 & 0.988 & 0.930 & 0.807 \\
10 & {$[57]$} & 0.983 & 0.980 & 0.392 & 0.981 & 0.980 & 1.861 & 0.990 & 0.906 & 0.278 \\
11 & {$[67]$} & 0.982 & 0.972 & 0.866 & 0.980 & 0.971 & 1.901 & 0.983 & 0.966 & 0.081 \\
\hline
\end{tabular}

\subsection{Evaluation of the Prediction Performance of RSM and ANN Model}

The RSM and ANN were used to model and predict the dicamba adoption capacity unto MIL-101(Cr). The results obtained from both models are in good agreement with the experimental findings in Table 6, but the ANN model performs better in comparison with the RSM. In every experimental condition selected in studying the adsorption process, the ANN model showed a better prediction with a high level of significance as well as validated the experimental results. The ANN has $\mathrm{R}^{2}=0.999, \mathrm{R}^{2}$ adj $=0.992$ and $\mathrm{RMSE}=0.053$, while for RSM, $R^{2}=0.990$ and $R^{2}$ adj $=0.979$. Less error is observed in the ANN model than the RSM. This is due to the fact that the ANN mimics the nervous system of the human by understanding the data combination, as well as generalizes the multivariate correlation between the experimental and the predicted variables. 
Table 6. Comparison between RSM and ANN model for predicting dicamba adsorption capacity.

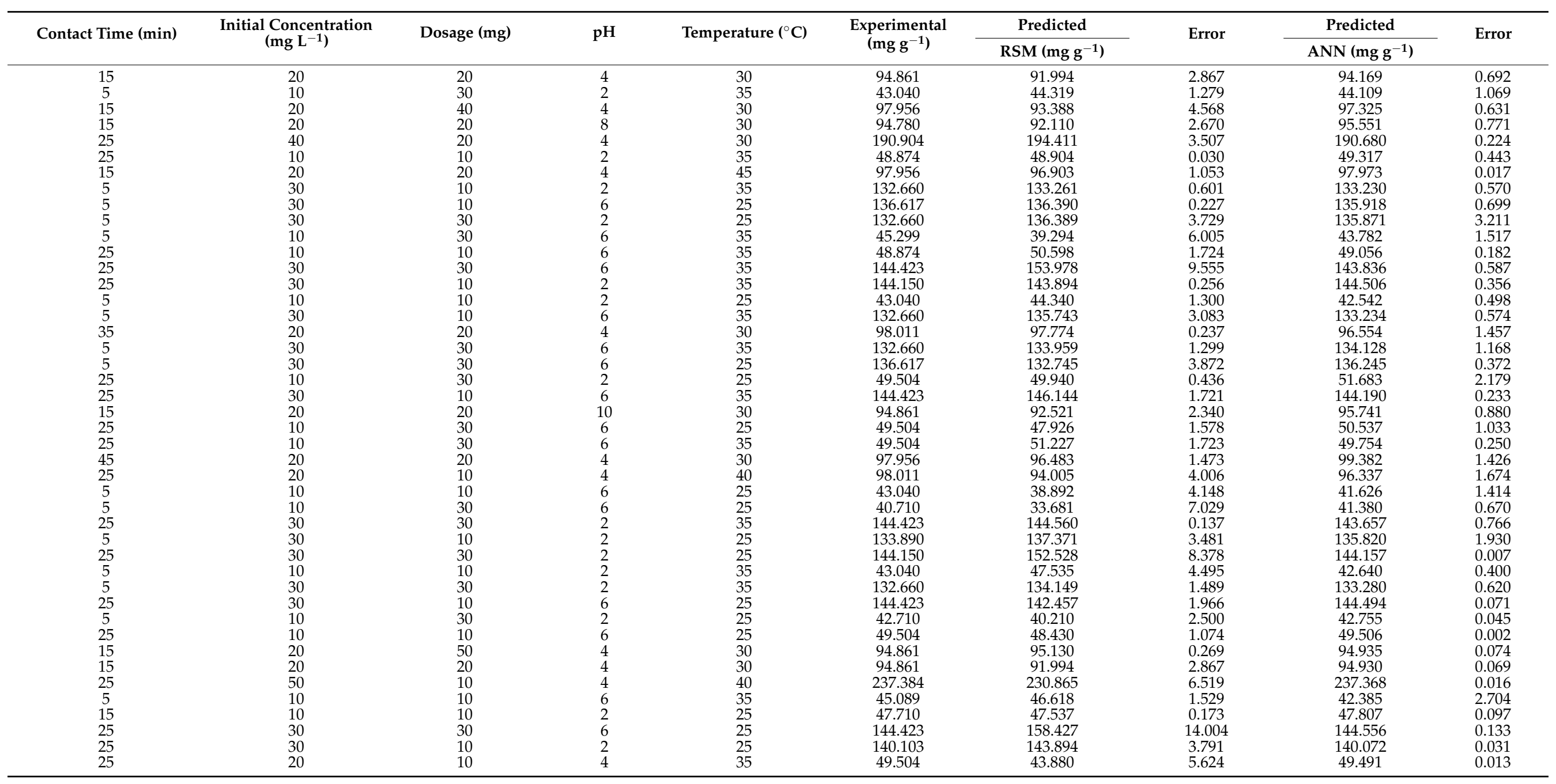




\subsection{Reusability Studies}

The feasibility for the repeated removal of dicamba in aqueous medium by MIL$101(\mathrm{Cr})$ was evaluated to determine the possibility of regeneration and reuse (Figure 7). High removal percentage was maintained by the adsorbent after the third cycle ( 99.4\%). A small decline in the removal $(2,5$, and $6 \%)$ is noticed after the fourth, fifth and sixth cycles, respectively. Nevertheless, the MOF retain $>90 \%$ removal efficiency even after the sixth cycle.

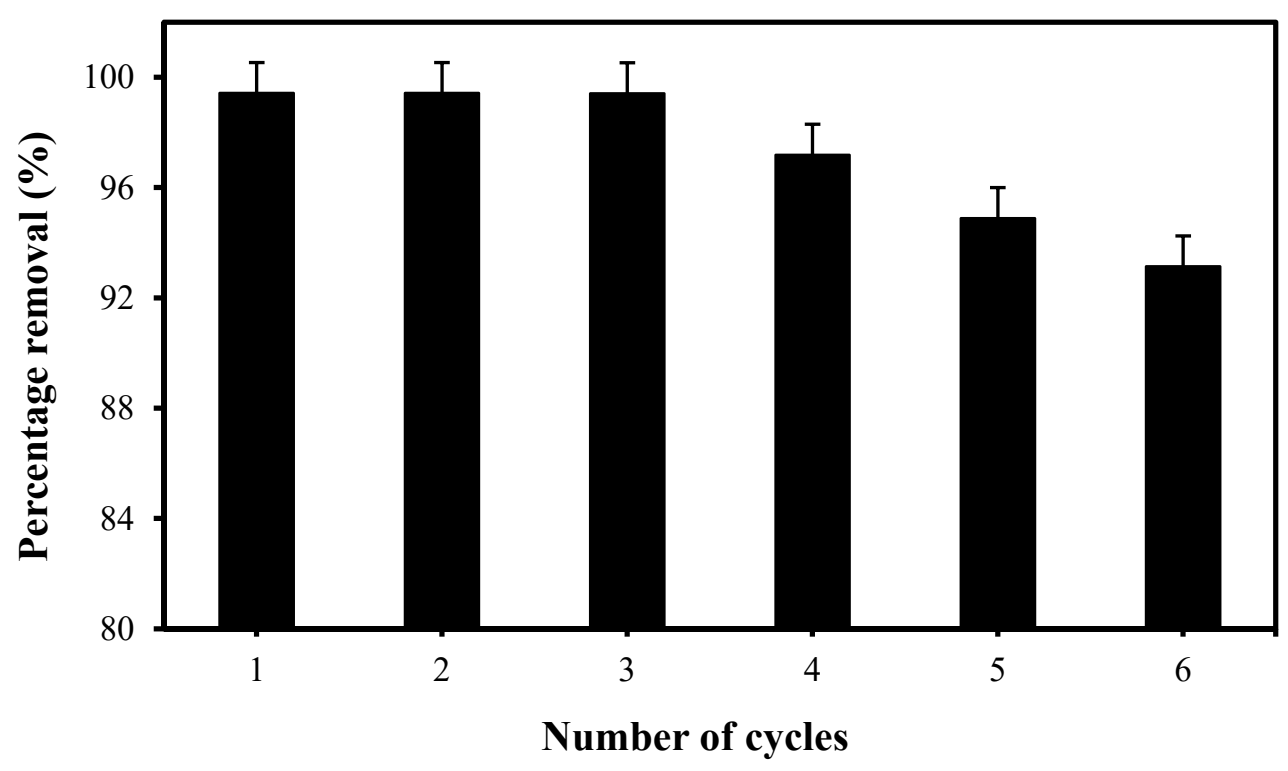

Figure 7. Reusability of MIL-101(Cr) adsorbent.

\subsection{Comparison with Different Adsorbents}

The adsorption characteristics of several adsorbent materials that were previously reported for the remediation of dicamba from aqueous medium are summarised in Table 7. MIL-10(Cr) adsorbent shows more superiority in terms of the surface area that is higher $\left(1439 \mathrm{~m}^{2} \mathrm{~g}^{-1}\right)$, adsorption capacity $\left(237.384 \mathrm{mg} \mathrm{g}^{-1}\right), \%$ removal efficiency $(99.432 \%)$, as well as fast equilibration time ( $25 \mathrm{~min})$. Comparison of reusability is not possible for the other adsorbents as it is not mentioned in all the earlier studies (Table 7).

Table 7. Comparison of different materials reported for the remediation of dicamba from water.

\begin{tabular}{|c|c|c|c|c|c|c|c|}
\hline Adsorbent & $\begin{array}{l}\text { Surface Area, } \\
\left(\mathrm{m}^{2} \mathrm{~g}^{-1}\right)\end{array}$ & Concentrations $\left(\mathrm{mg} \mathrm{L}^{-1}\right)$ & $(\%) R$ & $\begin{array}{c}Q_{\mathrm{e}} \\
\left(\mathrm{mg} \mathrm{g}^{-1}\right)\end{array}$ & Equilibrium Time (min) & Reuse & Ref. \\
\hline $\begin{array}{c}\text { Carbon } \\
\text { nanotubes }\end{array}$ & 600 & 50 & 86 & 21 & Not reported & $\begin{array}{c}\text { Not } \\
\text { reported }\end{array}$ & [38] \\
\hline Clay material & 204 & 50 & 80 & & 30 & $\begin{array}{c}\text { Not } \\
\text { reported }\end{array}$ & [39] \\
\hline $\begin{array}{l}\text { Mesoporous } \\
\text { carbon }\end{array}$ & 876 & 50 & NIL & 222 & 60 & $\begin{array}{l}\text { Not } \\
\text { reported }\end{array}$ & {$[40]$} \\
\hline $\begin{array}{c}\text { Vinyl and } \\
\mathrm{NH}_{2} @ \mathrm{COF}\end{array}$ & 336 & & 92 & 13 & Not reported & $\begin{array}{l}\text { Not } \\
\text { reported }\end{array}$ & {$[41]$} \\
\hline MIL-10(Cr) & 1439 & 50 & 99 & 237 & 25 & 6 & This work \\
\hline
\end{tabular}

\section{Conclusions}

A detailed evaluation of the optimization and adsorption of dicamba from aqueous solution was successfully demonstrated by using MIL-101(Cr). The adsorption best fitted the pseudo-second order kinetics and the Freundlich isotherm. The removal of dicamba was spontaneous and was endothermic in nature. The RSM and ANN models were used to optimize and model the adsorption process with a high level of significance. The shared interaction of the adsorption parameters were studied to understand the 
multivariate impact on the removal process. ANN gave better prediction with the highest coefficient of determination and minimum error for each studied experimental condition when compared with RSM. The adsorption capacity of dicamba $\left(\mathrm{qe}_{\mathrm{e}} \mathrm{g} \mathrm{g}^{-1}\right)$ is in good agreement with the experimental and calculated $\mathrm{q}_{\mathrm{e}}$ kinetics values. The MIL-101(Cr) displayed numerous advantageous features such as fast equilibration ( 25 min), high adsorption capacity $\left(237.384 \mathrm{mg} \mathrm{g}^{-1}\right)$, excellent percentage removal $(99.432 \%)$ and high surface area $\left(1439 \mathrm{~m}^{2} \mathrm{~g}^{-1}\right)$ when compared to other reported adsorbents. Furthermore, prospects for reusability were good as the adsorbent retained removal efficiency of $93 \%$ even after the sixth cycle. Commercial exploitation of this adsorbent must focus on production routes that are not only cost-effective but also environmentally benign.

Supplementary Materials: The following are available online at https:/ / www.mdpi.com/2227-9 717/9/3/419/s1, Figure S1: (a) Pseudo-second-order kinetics and (b) intraparticle diffusion model kinetics for dicamba adsorption (Dosage: $20 \mathrm{mg} ; 40{ }^{\circ} \mathrm{C}$; equilibrium time: $25 \mathrm{~min}, \mathrm{rpm}$ : 150); Table S1: Isotherm parameters for adsorption of dicamba onto MIL-101(Cr); Table S2: Coded range for independent variables for the CCD-RSM design matrix.

Author Contributions: Conceptualization, methodology, software, writing-original draft preparation, H.A.I.; validation, Z.U.Z.; resources, supervision, project administration and funding acquisition, K.J. and N.S.S.; formal analysis and visualization, J.W.L. and A.R.; writing-review and editing, H.A.I. and B.S. All authors have read and agreed to the published version of the manuscript.

Funding: This research was funded by the Fundamental Research Grant Scheme (FRGS-015MA0-127), Ministry of Higher Education (MOHE), Malaysia and Universiti Teknologi PETRONAS under the YUTP research grant cost center (015LCO-211) and UTP-UIR (015-MEO-166), FRGS/1/2020/STG04/UTP/02/3 Ministry of Higher Education (MOHE) grant.

Institutional Review Board Statement: Not applicable.

Informed Consent Statement: Not applicable.

Data Availability Statement: Not applicable.

Conflicts of Interest: The authors declare no conflict of interest.

\section{References}

1. Mojiri, A.; Zhou, J.L.; Robinson, B.; Ohashi, A.; Ozaki, N.; Kindaichi, T.; Farraji, H.; Vakili, M. Pesticides in aquatic environments and their removal by adsorption methods. Chemosphere 2020, 253, 126646. [CrossRef]

2. Yao, L.; Jia, X.; Zhao, J.; Cao, Q.; Xie, X.; Yu, L.; He, J.; Tao, Q. Degradation of the herbicide dicamba by two sphingomonads via different O-demethylation mechanisms. Int. Biodeterior. Biodegrad. 2015, 104, 324-332. [CrossRef]

3. Meftaul, I.M.; Venkateswarlu, K.; Dharmarajan, R.; Annamalai, P.; Megharaj, M. Pesticides in the urban environment: A potential threat that knocks at the door. Sci. Total Environ. 2020, 711, 134612. [CrossRef]

4. Huang, Y.; Yuan, L.; Reddy, K.N.; Zhang, J. In-situ plant hyperspectral sensing for early detection of soybean injury from dicamba. Biosyst. Eng. 2016, 149, 51-59. [CrossRef]

5. Gupta, P.K. Toxicity of Herbicides, 3rd ed.; Elsevier: Amsterdam, The Netherlands, 2018; pp. 553-567. [CrossRef]

6. De Arcaute, C.R.; Larramendy, M.L.; Soloneski, S. Genotoxicity by long-term exposure to the auxinic herbicides 2,4dichlorophenoxyacetic acid and dicamba on Cnesterodon decemmaculatus (Pisces: Poeciliidae). Environ. Pollut. 2018, 243, 670-678. [CrossRef] [PubMed]

7. Carmalin, S.A.; Lima, E.C. Removal of emerging contaminants from the environment by adsorption. Ecotoxicol. Environ. Saf. 2018, 150, 1-17. [CrossRef]

8. Ighalo, J.O.; Ajala, O.J.; Umenweke, G.; Ogunniyi, S.; Adeyanju, C.A.; Igwegbe, C.A.; Adeniyi, A.G. Mitigation of clofibric acid pollution by adsorption: A review of recent developments. J. Environ. Chem. Eng. 2020, 8, 104264. [CrossRef]

9. Singh, N.; Nagpal, G.; Agrawal, S. Rachna Water purification by using Adsorbents: A Review. Environ. Technol. Innov. 2018, 11, 187-240. [CrossRef]

10. Ghanizadeh, H.; Harrington, K.C.; James, T.K. A comparison of dicamba absorption, translocation and metabolism in Chenopodium album populations resistant and susceptible to dicamba. Crop. Prot. 2018, 110, 112-116. [CrossRef]

11. Beyki, T.; Asadollahzadeh, M.J. Selective removal of dicamba from aqueous samples using molecularly imprinted polymer nanospheres. J. Water Environ. Nanotechol. 2016, 1, 19-25. [CrossRef]

12. Azejjel, H.; Del Hoyo, C.; Draoui, K.; Rodríguez-Cruz, S.; Sánchez-Martín, M.J. Natural and modified clays from Morocco as sorbents of ionizable herbicides in aqueous medium. Desalination 2009, 249, 1151-1158. [CrossRef] 
13. Attari, M.; Bukhari, S.S.; Kazemian, H.; Rohani, S. A low-cost adsorbent from coal fly ash for mercury removal from industrial wastewater. J. Environ. Chem. Eng. 2017, 5, 391-399. [CrossRef]

14. Dhaka, S.; Kumar, R.; Deep, A.; Kurade, M.B.; Ji, S.-W.; Jeon, B.-H. Metal-organic frameworks (MOFs) for the removal of emerging contaminants from aquatic environments. Coord. Chem. Rev. 2019, 380, 330-352. [CrossRef]

15. Roy, D.; Neogi, S.; De, S. Adsorptive removal of heavy metals from battery industry effluent using MOF incorporated polymeric beads: A combined experimental and modeling approach. J. Hazard. Mater. 2020, 403, 123624. [CrossRef] [PubMed]

16. Rasheed, T.; Hassan, A.A.; Bilal, M.; Hussain, T.; Rizwan, K. Metal-organic frameworks based adsorbents: A review from removal perspective of various environmental contaminants from wastewater. Chemosphere 2020, 259, 127369. [CrossRef]

17. Yoo, D.K.; Bhadra, B.N.; Jhung, S.H. Adsorptive removal of hazardous organics from water and fuel with functionalized metal-organic frameworks: Contribution of functional groups. J. Hazard. Mater. 2020, 403, 123655. [CrossRef]

18. Zhao, H.Z.; Li, Q.; Wang, Z.; Wu, T.; Zhang, M. Synthesis of MIL-101(Cr) and its water adsorption performance. Microporous Mesoporous Mater. 2020, 297, 110044. [CrossRef]

19. Maksimchuk, N.V.; Zalomaeva, O.V.; Skobelev, I.Y.; Kovalenko, K.A.; Fedin, V.P.; Kholdeeva, O.A. Metal-organic frameworks of the MIL-101 family as heterogeneous single-site catalysts. Proc. R. Soc. A: Math. Phys. Eng. Sci. 2012, 468, 2017-2034. [CrossRef]

20. Férey, S.S.G.; Mellot-Draznieks, C.; Serre, C.; Millange, F.; Dutour, J.; Margiolaki, I. A chromium terephthalate-based solid with unusually large pore volumes and surface area. Science 2005, 309, 2040-2042. [CrossRef]

21. Pinheiro, D.; Pai, S.D.K.R.; Jose, A.; Bharadwaj, N.R.; Thomas, K. Effect of surface charge and other critical parameters on the adsorption of dyes on SLS coated $\mathrm{ZnO}$ nanoparticles and optimization using response surface methodology. J. Environ. Chem. Eng. 2020, 8, 103987. [CrossRef]

22. Isiyaka, H.A.; Jumbri, K.; Sambudi, N.S.; Zango, Z.U.; Ain, N.; Abdullah, F.; Saad, B.; Mustapha, A. Adsorption of dicamba and MCPA onto MIL-53(Al) metal-organic framework: Response surface methodology and artificial neural network model studies. RSC Adv. 2020, 10, 43213-43224. [CrossRef]

23. Zhu, S.; Khan, M.A.; Wang, F.; Bano, Z.; Xia, M. Exploration of adsorption mechanism of 2-phosphonobutane-1,2,4-tricarboxylic acid onto kaolinite and montmorillonite via batch experiment and theoretical studies. J. Hazard. Mater. 2020, 403, 123810. [CrossRef] [PubMed]

24. Chaturvedi, G.; Kaur, A.; Umar, A.; Khan, M.A.; Algarni, H.; Kansal, S.K. Removal of fluoroquinolone drug, levofloxacin, from aqueous phase over iron based MOFs, MIL-100(Fe). J. Solid State Chem. 2020, 281, 121029. [CrossRef]

25. Bahrami, M.; Amiri, M.J.; Bagheri, F. Optimization of the lead removal from aqueous solution using two starch based adsorbents: Design of experiments using response surface methodology (RSM). J. Environ. Chem. Eng. 2019, 7, 102793. [CrossRef]

26. Soleimanzadeh, H.; Niaei, A.; Salari, D.; Tarjomannejad, A.; Penner, S.; Grünbacher, M.; Hosseini, S.A.; Mousavi, S.M. Modeling and optimization of $\mathrm{V} 2 \mathrm{O} 5 / \mathrm{TiO} 2$ nanocatalysts for $\mathrm{NH}_{3}$-Selective catalytic reduction (SCR) of NOx by RSM and ANN techniques. J. Environ. Manag. 2019, 238, 360-367. [CrossRef]

27. Banerjee, P.; Sau, S.; Das, P.; Mukhopadhayay, A. Optimization and modelling of synthetic azo dye wastewater treatment using Graphene oxide nanoplatelets: Characterization toxicity evaluation and optimization using Artificial Neural Network. Ecotoxicol. Environ. Saf. 2015, 119, 47-57. [CrossRef]

28. Altowayti, W.A.H.; Algaifi, H.A.; Abu Bakar, S.; Shahir, S. The adsorptive removal of As (III) using biomass of arsenic resistant Bacillus thuringiensis strain WS3: Characteristics and modelling studies. Ecotoxicol. Environ. Saf. 2019, 172, 176-185. [CrossRef]

29. Yusuf, M.; Song, K.; Li, L. Fixed bed column and artificial neural network model to predict heavy metals adsorption dynamic on surfactant decorated graphene. Coll. Surf. A 2020, 585, 124076. [CrossRef]

30. Shadmehr, J.; Zeinali, S.; Tohidi, M. Synthesis of a chromium terephthalate metal organic framework and use as nanoporous adsorbent for removal of diazinon organophosphorus insecticide from aqueous media. J. Dispers. Sci. Technol. 2019, 40, 1423-1440. [CrossRef]

31. Karmakar, S.; Roy, D.; Janiak, C.; De, S. Insights into multi-component adsorption of reactive dyes on MIL-101-Cr metal organic framework: Experimental and modeling approach. Sep. Purif. Technol. 2019, 215, 259-275. [CrossRef]

32. Alivand, M.S.; Shafiei-Alavijeh, M.; Tehrani, N.H.M.H.; Ghasemy, E.; Rashidi, A.; Fakhraie, S. Facile and high-yield synthesis of improved MIL-101(Cr) metal-organic framework with exceptional $\mathrm{CO}_{2}$ and $\mathrm{H}_{2} \mathrm{~S}$ uptake; the impact of excess ligand-cluster. Microporous Mesoporous Mater. 2019, 279, 153-164. [CrossRef]

33. Niknam, E.; Panahi, F.; Daneshgar, F.; Bahrami, F.; Khalafi-Nezhad, A. Metal-Organic Framework MIL-101(Cr) as an Efficient Heterogeneous Catalyst for Clean Synthesis of Benzoazoles. ACS Omega 2018, 3, 17135-17144. [CrossRef] [PubMed]

34. Liu, Q.; Ning, L.; Zheng, S.; Tao, M.; Shi, Y.; He, Y. Adsorption of Carbon Dioxide by MIL-101(Cr): Regeneration Conditions and Influence of Flue Gas Contaminants. Sci. Rep. 2013, 3, 1-6. [CrossRef] [PubMed]

35. Gao, Y.; Liu, K.; Kang, R.; Xia, J.; Yu, G.; Deng, S. A comparative study of rigid and flexible MOFs for the adsorption of pharmaceuticals: Kinetics, isotherms and mechanisms. J. Hazard. Mater. 2018, 359, 248-257. [CrossRef]

36. Shahnaz, T.; Sharma, V.; Subbiah, S.; Narayanasamy, S. Multivariate optimisation of Cr (VI), Co (III) and Cu (II) adsorption onto nanobentonite incorporated nanocellulose/chitosan aerogel using response surface methodology. J. Water Process. Eng. 2020, 36, 101283. [CrossRef]

37. Zhou, M.; Wu, Y.-N.; Qiao, J.; Zhang, J.; McDonald, A.; Li, G.; Li, F. The removal of bisphenol A from aqueous solutions by MIL-53(Al) and mesostructured MIL-53(Al). J. Coll. Interface Sci. 2013, 405, 157-163. [CrossRef] 
38. Pyrzyńska, K.; Stafiej, A.; Biesaga, M. Sorption behavior of acidic herbicides on carbon nanotubes. Microchim. Acta 2007, 159, 293-298. [CrossRef]

39. You, Y.; Zhao, H.; Vance, G.F. Adsorption of dicamba (3,6-dichloro-2-methoxy benzoic acid) in aqueous solution by calcinedlayered double hydroxide. Appl. Clay Sci. 2002, 21, 217-226. [CrossRef]

40. Pinto, M.D.C.E.; Gonçalves, R.G.L.; Dos Santos, R.M.M.; Araújo, E.A.; Perotti, G.F.; Macedo, R.D.S.; Bizeto, M.A.; Constantino, V.R.L.; Pinto, F.G.; Tronto, J. Mesoporous carbon derived from a biopolymer and a clay: Preparation, characterization and application for an organochlorine pesticide adsorption. Microporous Mesoporous Mater. 2016, 225, 342-354. [CrossRef]

41. Ji, W.-H.; Guo, Y.-S.; Wang, X.; Lu, X.-F.; Guo, D.-S. Amino-modified covalent organic framework as solid phase extraction absorbent for determination of carboxylic acid pesticides in environmental water samples. J. Chromatogr. A 2019, 1595, 11-18. [CrossRef] 